\title{
Purification of Crocin-I from Gardenia Yellow by Macroporous Resin Columns In-Series and Its Antidepressant-Like Effect
}

\author{
Yu Jiang $\mathbb{D}^{1},{ }^{1}$ Susu Lin $\mathbb{D}^{1},{ }^{1}$ Qiaoqiao Li $\mathbb{D}^{1},{ }^{1}$ Yingpeng Tong $\mathbb{D}^{2},{ }^{2}$ and Ping Wang $\mathbb{D}^{1}$ \\ ${ }^{1}$ College of Pharmaceutical Sciences, Zhejiang University of Technology, Hangzhou 310014, China \\ ${ }^{2}$ Institute of Natural Medicine and Health Product, School of Advanced Study, Taizhou University, Taizhou 318000, China \\ Correspondence should be addressed to Yingpeng Tong; fish166@tzc.edu.cn and Ping Wang; wangping45@zjut.edu.cn
}

Received 17 September 2021; Revised 11 December 2021; Accepted 30 December 2021; Published 18 January 2022

Academic Editor: Sedat Yurdakal

Copyright $\odot 2022$ Yu Jiang et al. This is an open access article distributed under the Creative Commons Attribution License, which permits unrestricted use, distribution, and reproduction in any medium, provided the original work is properly cited.

In this study, the purification of crocin-I from Gardenia yellow by macroporous resin columns in-series was systematically investigated. The in-series macroporous adsorption resins consisting of XAD 4 and XAD $1600 \mathrm{~N}$ resins were selected on the basis of the evaluation of performance and separation characteristics of 17 kinds of resins, including the adsorption capacities, desorption ratio, and separation degree. According to the analysis results, the optimum conditions were as follows: bed volume ratio of XAD 4 and XAD $1600 \mathrm{~N}$ resins, sample volume, flow rate, and methanol concentration were $3: 1,5 \mathrm{BV}, 15 \mathrm{BV} / \mathrm{h}$, and $70 \%$, respectively (BV was the bed volume of XAD 4 resin). After one run treatment, the separation degree of crocin-I at $254 \mathrm{~nm}$ and $440 \mathrm{~nm}$ decreased from 1.92 to $0.08\left(D_{C-254 \mathrm{~nm}}\right)$ and from 0.71 to $0.36\left(D_{C-440 \mathrm{~nm}}\right)$, respectively. The results showed that the inseries macroporous resins revealed a high capacity in the purification of crocin-I. Meanwhile, in the animal experiment, the forced swimming tests were regulated by crocin-I and Gardenia yellow, which demonstrated that crocin-I was the main constituent of Gardenia yellow and had potential antidepressant biological activities.

\section{Introduction}

Fructus Gardenia, also known as zhizi (秨子) in China, is the dried fruit of Gardenia jasminoides Eills [1, 2]. As a traditional Chinese medicine, it is widely used in the clinical treatment of jaundice, coronary heart disease, infantile fever, contusion, and other diseases, including the main bioactive ingredients of iridoids, Gardenia yellow, organic acid, and so on [3,4]. Gardenia yellow is a mixture of total crocetin derivatives which could be extracted from Fructus Gardenia by aqueous ethanol solution [5] and then purified by macroporous resins [6] or gel chromatography. Meanwhile, it is a water-soluble pigment and is extensively applied in the food, dye, and cosmetic industries [7].

Crocin-I (Figure 1), a digentiobiosyl ester of crocetin [8], is the most abundant ingredient in Gardenia yellow, which is also the active ingredient with the highest content in saffron. $\mathrm{Nu}^{-}$ merous studies have confirmed that crocin-I exhibits various pharmacological properties on cerebral ischemia $[9,10]$, depression [11], anxiety [12], atherosclerosis [13], hyperlipidemia [14], hypertension [15], and other diseases [16-18]. And it can also be used for enhancing abilities of learning and memory [19], antinociceptive [20], anti-inflammatory [20], and antitumor effects [21].

A great number of methods have been adopted to purify crocin-I from saffron, Fructus Gardenia or Gardenia yellow, including silica gel, preparative TLC (thin layer chromatography) [22], sephadex gel [23], preparative C18 HPLC (high performance liquid chromatography) [24], semipreparative low-pressure liquid chromatography [25], macroporous resins $[26,27]$, and high-speed countercurrent chromatography [28]. Among them, macroporous resin chromatography has been confirmed to be a fast, low-cost, high-yield, certain-selectivity, and environmentally friendly purification method, which can be easily used in industrialscale manufacture [29]. Furthermore, the macroporous adsorption resins have the advantages of good stability, easy regeneration, and long lifetime [30]. So far, there have been some researchers who adapted the approach of macroporous resins to purify crocins from the Fructus Gardenia. Chen et al. [7] evaluated the performance and separation characteristics of nine macroporous resins and chose HPD722 to 


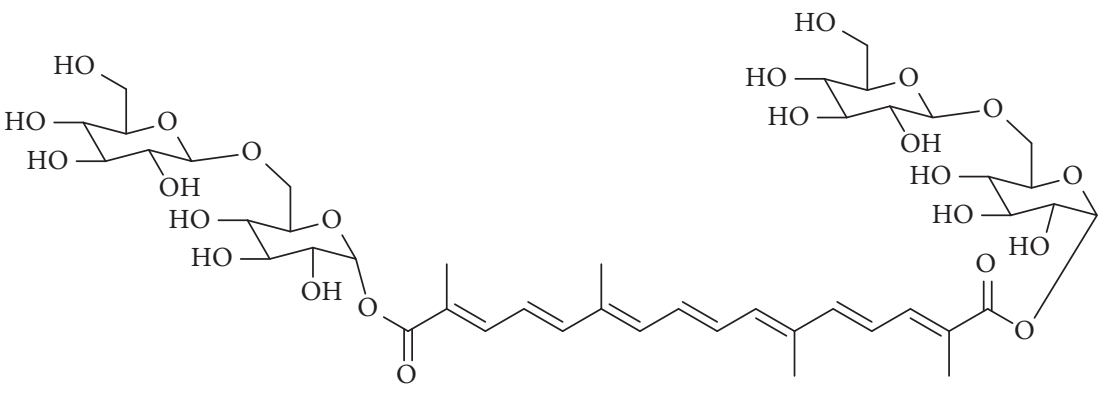

FIgURE 1: The chemical structure of crocin-I.

purify Gardenia yellow from Gardenia jasminoides var. owing to its strong adsorption and desorption capacity as well as high selectivity.

As shown in the literature, the adsorption process of macroporous resins is a multilayer adsorption process through intermolecular hydrogen bonds and Van der Waals' force, with the inductive effect transmitted from the first layer to a higher layer or multilayers [31]. And macroporous resins often achieve chemical modification by introducing special functional groups into the matrix of the polymeric adsorbents, which can improve the adsorption capacity for organic compounds and obtain a higher adsorption selectivity for some specific organic compounds by modifying the chemical composition of absorbent surface [32]. The traditional techniques of macroporous resins are usually carried out with only one resin chosen by adsorption and desorption properties, but the broad-spectrum separation characteristics of resins always lead to lower purity and more operational processes. Thus, some researchers created novel and highly efficient approaches by using two or more kinds of macroporous resins to purify the target bioactive compounds, such as a multichannel parallel-serial chromatographic system packed with macroporous resins [31], mixedmode macroporous resins by a physical blending method [33], a mixed bed of macroporous resins [34-36], and so on. Therefore, investigations of the mixed and simultaneous use of macroporous resins are of great importance.

According to statistics, there are some biological samples purified by the resins mixed bed, which have been widely applied in industrial-scale manufacturing because of their high separation selectivity and production efficiency. But crocin-I has not been purified through these methods yet. By the way, there are still no reports on using macroporous resin column in-series to separate and enrich crocin-I from Gardenia yellow, which may be informative for the purification of natural products from complex plant extracts. In our study, we carried out the study with macroporous resin columns in-series to significantly increase the purity of crocin-I from Gardenia yellow through investigation of resin selection and optimization of the bed volume ratio of in-series macroporous resins, sample volume, flow rate, and methanol concentration. Then, we compared the antidepressant-like effects of crocin-I and Gardenia yellow following subacute administration (for 10 days) to ensure whether crocin-I was the main antidepressant compound of Gardenia yellow. Fluoxetine, a selective reuptake inhibitor of 5-HT (serotonin), was administered as a positive control group. The behavioral model for depression evaluation was the forced swimming test, and the weight, AST (aspartate aminotransferase), and ALT (alanine aminotransferase) of mice were performed to investigate for adverse effects.

\section{Material and Methods}

2.1. Chemicals, Reagents, and Adsorbents. Gardenia yellow was purchased from Henan Yongshun Chemical Co., Ltd. (Henan, China, no: 20170506). Crocin-I and fluoxetine were obtained from Shanghai Yuanye Bio-Technology Co., Ltd. (Shanghai, China). The HPLC-grade methanol was supplied by Tedia Company, Inc. (Shanghai, China). All other reagents were of analytical grade.

Macroporous resins including ADS-7, XAD 7HP, D101, ADS-17, XAD 16, XAD 4, XAD 1600N, AB-8-II, XAD 761, HP 20, XAD 18, HP2MGL, SP 825, SP 70, SP 700, HP 21, and SP 207 were provided from H\&E Co., Ltd. (Beijing, China). The physical and chemical properties are listed in Table 1. Before use, the resins were pretreated by soaking in ethanol for $24 \mathrm{~h}$ and then washed with ultrapure water to remove the monomers and porogenic agents.

2.2. Animals. C57BL/6 mice, male, weighing 18-24 g, were purchased from Shanghai Shrike Experimental Animal Co., Ltd. (Shanghai, China). The experimental animals were all bred at the Experimental Animal Center of Zhejiang University of Technology with license No. SCXK (Zhejiang) 2008-0033. Breeding rooms were kept well ventilated and lighting was provided for $12 \mathrm{~h}$ per day at a temperature of 22 to $25^{\circ} \mathrm{C}$ with a humidity of $60 \%-70 \%$. All the mice were fed for 1 week to adapt to the environment and were weighed to remove mice that were underweight or overweight to conduct the following tests.

2.3. HPLC Analysis of Samples. All samples were performed on an Agilent ODS $\mathrm{C}_{18}$ column $(150 \times 4.6 \mathrm{~mm}, 5 \mu \mathrm{m})$ by using an Agilent $1260 \mathrm{HPLC}$ system at $30^{\circ} \mathrm{C}$. The injection volume was $10 \mu \mathrm{L}$, and the wavelength of the DAD (diode array detector) was set at $254 \mathrm{~nm}$ and $440 \mathrm{~nm}$. The mobile phase consisted of methanol (solvent A) and water (solvent $\mathrm{B})$, and the gradient was gradually changed from $45 \%$ A to $85 \%$ A within $20 \mathrm{~min}$ at a flow rate of $1.0 \mathrm{~mL} / \mathrm{min}$. Visibly, the HPLC chromatogram of Gardenia yellow at $254 \mathrm{~nm}$ is shown in Figure 2. The calibration curve of crocin-I 
TABLE 1: Physical and chemical properties of the test macroporous resins.

\begin{tabular}{|c|c|c|c|c|c|c|}
\hline Macroporous resins & Material & Polarity & $\begin{array}{c}\text { Pore } \\
\text { diameter }(\mathrm{nm})\end{array}$ & $\begin{array}{c}\text { Particle } \\
\text { size }(\mathrm{mm})\end{array}$ & $\begin{array}{c}\text { Specific surface } \\
\text { area }\left(\mathrm{m}^{2} / \mathrm{g}\right)\end{array}$ & $\begin{array}{c}\text { Moisture } \\
\text { content (\%) }\end{array}$ \\
\hline XAD 7HP & Acrylate & SP & 45 & 0.56 & 500 & 68.34 \\
\hline ADS-17 & Acrylic ester & MP & $25-30$ & $0.30-1.25$ & $90-120$ & 57.54 \\
\hline XAD-16 & Polystyrene & $\mathrm{NP}$ & 15 & 0.70 & 800 & 67.00 \\
\hline XAD 4 & SDVB & NP & $30-40$ & $0.4-0.6$ & 750 & 59.19 \\
\hline XAD $1600 N$ & SDVB & NP & 15 & $0.35-0.45$ & 800 & 69.47 \\
\hline AB-8-II & Polystyrene & WP & - & - & - & 68.06 \\
\hline HP-2MGL & Methacrylate & MP & 34 & $>0.35$ & 470 & 65.07 \\
\hline HP 21 & SDVB & NP & - & $>0.25$ & 640 & 59.52 \\
\hline SP 207 & Polystyrene & NP & 21 & 0.25 & 630 & 52.68 \\
\hline ADS-7 & Amidocyanogen & SP & $25-30$ & $0.30-1.25$ & $100-120$ & 68.21 \\
\hline D101 & Polystyrene & NP & $9-10$ & $0.25-0.84$ & $500-550$ & 70.48 \\
\hline XAD 761 & Phenolic & SP & 60 & $0.56-0.76$ & 150 & 62.88 \\
\hline HP-20 & Polystyrene & WP & 52 & $>0.25$ & 600 & 59.68 \\
\hline XAD 18 & SDVB & NP & 15 & $0.38-0.48$ & 800 & 64.52 \\
\hline SP-825 & Polystyrene & WP & 11.4 & $>0.25$ & 1050 & 59.87 \\
\hline SP 70 & SDVB & WP & 14 & 0.50 & 885 & 64.25 \\
\hline SP 700 & SDVB & NP & 8.1 & $>0.25$ & 1200 & 71.97 \\
\hline
\end{tabular}

SDVB: styrene divinyl-benzene; SP: strong polar; MP: moderately polar; WP: weakly polar; NP: nonpolar.

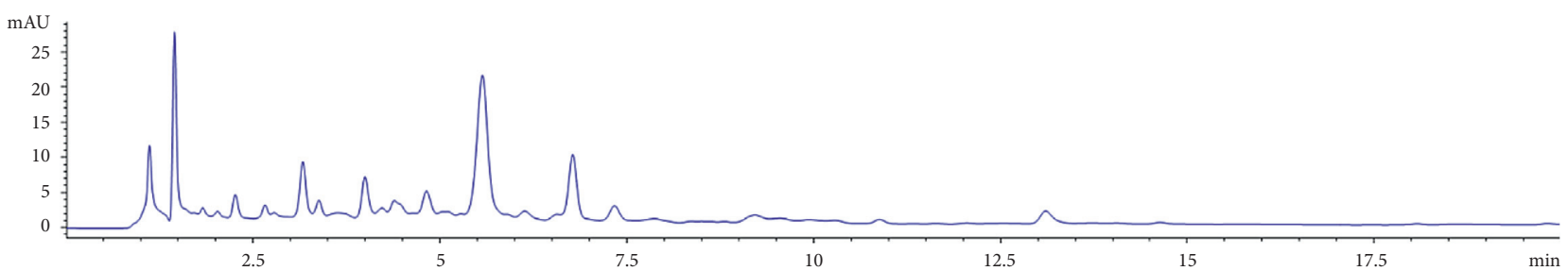

(a)

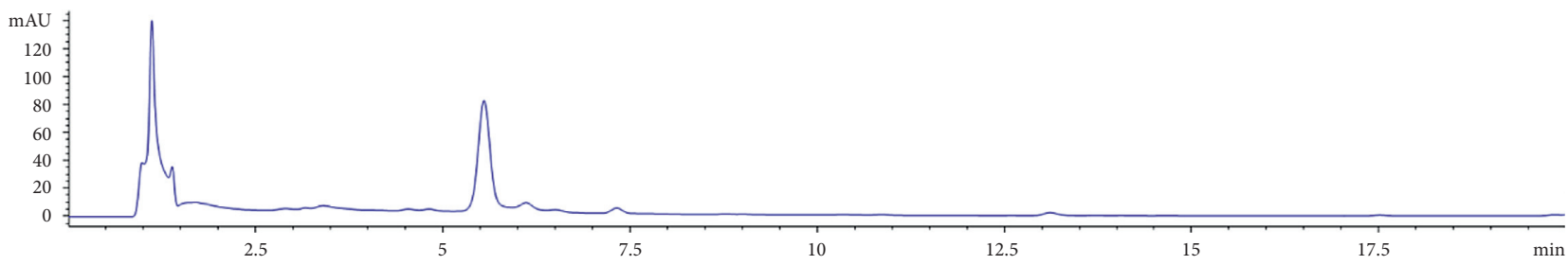

(b)

FiguRE 2: HPLC chromatograms of Gardenia yellow (a) and eluate of macroporous resin columns in-series with optimal conditions (b) at $254 \mathrm{~nm}$.

$(P=6177.2 C+181.17)$ was obtained in the range of $0.104-1.56 \mathrm{mg} / \mathrm{mL}$ with good linearity $\left(R^{2}>0.9993\right)$, where $P$ represented the peak area of crocin-I at $440 \mathrm{~nm}$ and $C$ represented its concentration in the standard solution (mg/ $\mathrm{mL})$.

2.4. Adsorption and Desorption Experiments. The adsorption and desorption experiments were carried out as follows: pretreated macroporous resins (equal to $0.500 \mathrm{~g}$ dry resins) and $40 \mathrm{~mL}$ of $20 \mathrm{mg} / \mathrm{mL}$ Gardenia yellow were put into centrifuge tubes, which were shaken at room temperature for $12 \mathrm{~h}$. After washing with ultrapure water three times, the resins were soaked with a $20 \mathrm{~mL}$ methanol solution in centrifuge tubes and shaken at room temperature for $12 \mathrm{~h}$. The solutions were diluted with an equal amount of water and analyzed by HPLC, respectively. The adsorption capacities and desorption ratios are calculated by

$$
\begin{gathered}
Q_{t}=\frac{\left(C_{0}-C_{t}\right) \times V_{0}}{M}, \\
D_{t}=\frac{C_{d} \times V_{d}}{Q_{t} \times M} \times 100 \%,
\end{gathered}
$$

where $Q_{t}$ is the resin adsorption capacity of crocin-I at time $t$ $(\mathrm{mg} / \mathrm{g}) ; D_{t}$ is the desorption ratio of resins (\%); $\mathrm{C}_{0}, C_{t}$, and $C_{d}$ represent the crocin-I content of the sample solution at the beginning, at time $t$, and the desorption solution, respectively (mg/mL); $V_{0}$ and $V_{d}$ denote the volume of the adsorption and desorption solutions added to the centrifuge tubes $(\mathrm{mL})$, respectively; and $M$ represents the weight of the dry resins $(\mathrm{g})$. 
2.5. Purification Process Optimization of Crocin-I by Macroporous Resins Columns In-Series. According to the results of adsorption and desorption experiments, two types of resins were packed into the macroporous resin columns inseries (Figure 3), respectively. Then, the effects of selected macroporous resins (XAD 4 XAD 1600N, XAD 4 ADS-7, $\mathrm{XAD} 4 \sim \mathrm{HP} 2 \mathrm{MGL}$, and XAD 4 XAD 7HP), elute rate (5-30 $\mathrm{BV} / \mathrm{h})$, sample volume (2.5-15 BV), bed volume ratio of resins $(1: 1-5: 1)$, and methanol concentration $(40-80 \%)$ on the purity and yield of crocin-I were investigated.

\subsection{Antidepressant-Like Effect of Crocin-I and Gardenia Yellow}

2.6.1. Grouping and Administration. 88 mice were divided into 8 groups randomly, and each experimental group contained 11 mice. The groups were as follows: Group I (ultrapure water control group; $0.1 \mathrm{~mL} / 10 \mathrm{~g}$ ), Group II-IV (crocin-I; 20, 40, and $80 \mathrm{mg} / \mathrm{kg}$ ), Group V-VII (Gardenia yellow; 30, 70, and $120 \mathrm{mg} / \mathrm{kg}$ ), and Group VIII (fluoxetine; $20 \mathrm{mg} / \mathrm{kg}$ ). All drugs were given by intragastric (i.g.) administration at 10-11 a.m. for 10 days.

2.6.2. Behaviour Tests. In the study, animals were evaluated in the forced swimming test (FST). The behaviour tests were carried out $1 \mathrm{~h}$ after administration. The forced swimming test was performed on the $11^{\text {th }}$ day after the pretest on the $10^{\text {th }}$ day in order to minimize the interference of tests because the FST is a more stressful task than the tail suspension test [37].

2.7. Statistical Analysis. All data of animal experiments were expressed as mean $(\bar{X}) \pm$ standard deviation (S). Statistical analysis was performed using the SPSS (statistical product and service solutions) software, and the difference between groups was considered statistically significant when $p<0.05$.

\section{Results and Discussions}

3.1. Adsorption and Desorption Experiments. The optimum macroporous resins were preliminary evaluated by their adsorption and desorption abilities, and separation degrees $\left(D_{C-254 \mathrm{~nm}}\right.$ and $\left.D_{C-440 \mathrm{~nm}}\right)$ for crocin-I are given by

$$
\begin{gathered}
D_{C-254 \mathrm{~nm}}=\frac{P_{I-254 \mathrm{~nm}},}{P_{C-254 \mathrm{~nm}}} \\
D_{C-440 \mathrm{~nm}}=\frac{P_{I-440 \mathrm{~nm}}}{P_{C-440 \mathrm{~nm}}},
\end{gathered}
$$

where $D_{C-254 \mathrm{~nm}}$ represents the separation degree between crocin-I and impurities which were shown at $254 \mathrm{~nm}$ but not shown at $440 \mathrm{~nm} ; D_{C-440 \mathrm{~nm}}$ represents the separation degree between crocin-I and impurities only shown at $440 \mathrm{~nm}$; and $P_{C-254 \mathrm{~nm}}, P_{C-440 \mathrm{~nm}}, P_{I-254 \mathrm{~nm}}$, and $P_{I-440 \mathrm{~nm}}$ represent the peak areas of crocin-I shown at $254 \mathrm{~nm}$, crocin-I shown at $440 \mathrm{~nm}$, impurities shown at $254 \mathrm{~nm}$, but not shown at $440 \mathrm{~nm}$, and impurities shown at $440 \mathrm{~nm}$, respectively.

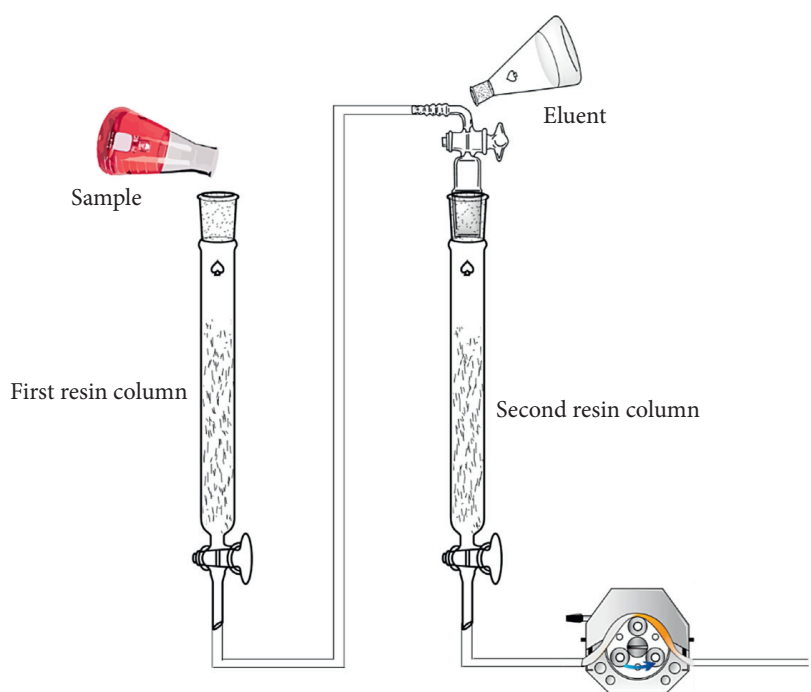

FIgURE 3: The schematic figure of macroporous resin columns inseries.

Except $D_{C-254 \mathrm{~nm}}$ and $D_{C-440 \mathrm{~nm}}$, recovery ratio $(R)$ was also confirmed as the index to screen optimal macroporous resins, because the meaning of high recovery ratio is resource conservation and more production, which is given by

$$
R=\frac{C_{d c} \times V_{d}}{C_{i c} \times V_{i}},
$$

where $R(\%)$ represents the recovery ratio of crocin-I from Gardenia yellow; $C_{d c}$ and $C_{i c}$ represent the concentration of crocin-I in the desorption solution and initial solution, respectively $(\mathrm{mg} / \mathrm{mL})$; and $V_{d}$ and $V_{i}$ represent the volume of desorption solution and initial solution, respectively $(\mathrm{mL})$.

When the content of impurities notably became lower with a higher decreasing extent than the content change of crocin-I, $D_{C-254 \mathrm{~nm}}$ and $D_{C-440 \mathrm{~nm}}$ would be reduced, which means that the purity of crocin-I increased after treatment of macroporous resin columns in-series. On the contrary, when the purity of crocin-I decreased, $D_{C-254 \mathrm{~nm}}$ and $D_{C-440 \mathrm{~nm}}$ would become larger. Thus, $D_{C-254 \mathrm{~nm}}$ and $D_{C-440 \mathrm{~nm}}$ were as small as possible, displaying the application effect of macroporous resin columns in-series intuitively.

The results of adsorption capacities $\left(Q_{t}\right)$, desorption ratio $(D)$, and separation degree $\left(D_{C-254 \mathrm{~nm}}\right.$ and $\left.D_{C-440 \mathrm{~nm}}\right)$ are shown in Table 2. The adsorption capacities order of optimal five kinds of macroporous resins was XAD $1600 \mathrm{~N}>\mathrm{SP}$ $700>\mathrm{XAD} 16>\mathrm{D} 101>\mathrm{AB}-8$-II, the desorption ratio order of optimal five kinds of macroporous resins was HP $21>$ ADS $17>$ XAD $4>$ SP $207>$ XAD 18, and the separation degree order of crocin-I in $254 \mathrm{~nm}$ and $440 \mathrm{~nm}$ were XAD $4<$ SP $\quad 825<$ SP $\quad 207<$ SP $\quad 700<\mathrm{XAD} \quad 18$ and $\mathrm{XAD}$ $1600 \mathrm{~N}<$ ADS- $>$ HP $2 \mathrm{MGL}<\mathrm{XAD} \quad 7 \mathrm{HP}<$ ADS 17 , respectively. Compared with the initial solution, the $D_{C-254 \mathrm{~nm}}$ of raffinate after being absorbed by XAD 4 became significantly lower, showing that this resin had good performance for the adsorption ability of impurities shown at $254 \mathrm{~nm}$, but not shown at $440 \mathrm{~nm}$, which might be determined as monoterpenoids of Gardenia yellow. Meanwhile, the 
TABLE 2: Adsorption properties of crocin-I on 17 kinds of macroporous resins.

\begin{tabular}{|c|c|c|c|c|}
\hline Macroporous resins & $Q_{t}(\mathrm{mg} / \mathrm{g})$ & $D_{t}$ & $D_{C-254 \mathrm{~nm}}$ & $D_{C-440 \mathrm{~nm}}$ \\
\hline XAD 7HP & 436.43 & 98.38 & 2.25 & 0.31 \\
\hline ADS-17 & 135.48 & 111.14 & 0.99 & 0.39 \\
\hline XAD-16 & 448.76 & 99.07 & 0.77 & 0.49 \\
\hline XAD 4 & 139.42 & 106.19 & 0.25 & 0.70 \\
\hline XAD $1600 \mathrm{~N}$ & 514.42 & 91.36 & 7.49 & 0.20 \\
\hline AB-8-II & 441.28 & 103.81 & 1.36 & 0.36 \\
\hline HP-2MGL & 394.3 & 97.32 & 1.89 & 0.28 \\
\hline HP 21 & 364.93 & 113.45 & 0.79 & 0.55 \\
\hline SP 207 & 274.94 & 104.86 & 0.47 & 0.65 \\
\hline ADS-7 & 407.99 & 87.45 & 2.26 & 0.24 \\
\hline D101 & 446.4 & 99,61 & 1.45 & 0.38 \\
\hline XAD 761 & 267.16 & 100.18 & 0.65 & 1.47 \\
\hline HP-20 & 395.91 & 101.25 & 1.12 & 0.39 \\
\hline XAD 18 & 419.37 & 104.76 & 0.59 & 0.61 \\
\hline SP-825 & 369.69 & 101.33 & 0.37 & 0.62 \\
\hline SP 70 & 419.34 & 101.85 & 0.65 & 0.63 \\
\hline SP 700 & 486.96 & 94.52 & 0.48 & 0.74 \\
\hline Gardenia yellow & & & 1.92 & 0.71 \\
\hline
\end{tabular}

$D_{\mathrm{C}-440 \mathrm{~nm}}$ of raffinates after absorbed by XAD $1600 \mathrm{~N}$, ADS7, HP2MGL, and XAD 7HP became lower than that of the initial solution, which indicated that these four kinds of macroporous resins had better performance in the adsorption abilities of impurities shown at $440 \mathrm{~nm}$. The adsorption characteristics of impurities and crocin-I on resins are not only related to the polarity, functional groups, and structure of impurities and crocin-I, but also associated with the specific surface area, pore diameter, and polarity of resins. The XAD 4 macroporous resin with SDVB material is always used to remove organic solvents and small molecular nonpolar substances. Substances are absorbed into the pore wall of this resin under the action of intermolecular force and hydrophobicity, which is tightly correlated with the pore size. Impurities shown at $254 \mathrm{~nm}$ of Gardenia yellow could be easily absorbed by nonpolar XAD 4 resins with a pore diameter of $35 \mathrm{~nm}$, which only absorb a little substance shown at $440 \mathrm{~nm}$ of Gardenia yellow, including crocin-I and structure similar impurities. Thus, XAD 4 resins were chosen as the first resins of the in-series macroporous resins because they could adsorb the impurities shown at $254 \mathrm{~nm}$ more and adsorb crocin-I less at the same time, making the $\mathrm{D}_{\mathrm{C}-254 \mathrm{~nm}}$ reduce significantly. Meanwhile, XAD $1600 \mathrm{~N}$, ADS-7, HP2MGL, and XAD 7HP resins are all formed by different materials to possess different polarity, pore diameter, specific surface area, and particle size. And they possessed good adsorption and desorption capacity for crocin-I with different characteristics of their own. Through summary of the abovementioned data, XAD 1600N, ADS-7, HP2MGL, and $\mathrm{XAD} 7 \mathrm{HP}$ resins were chosen as the optional second resins of the in-series macroporous resins to continue the following experiments.

3.2. Selection of Resins. On basis of the abovementioned experiments, XAD 4 resin was chosen to be installed in series with XAD $1600 \mathrm{~N}$, ADS-7, HP2MGL, and XAD 7HP resins, respectively. The elute rate, sample volume, bed volume ratio of resins, and methanol concentration were set as $15 \mathrm{BV} / \mathrm{h}$, 20 BV, $1: 1$, and 70\%, respectively. As shown in Table 3, inseries macroporous resins with the XAD 4 and XAD $1600 \mathrm{~N}$ resins could decrease $D_{C-254 \mathrm{~nm}}$ and $D_{C-440 \mathrm{~nm}}$ more significantly, compared with other combinations of in-series macroporous resins, due to their polarity and dimensional structure, which could make themselves adsorb more impurities and desorb less impurities. XAD $1600 \mathrm{~N}$, with a pore diameter of about $15 \mathrm{~nm}$, is a kind of neutral resin without active groups on the surface. And its adsorption capacity is closely related to the pore size for suitable molecules. Crocin-I and impurities shown at $440 \mathrm{~nm}$ were suitable for the pore size of XAD $1600 \mathrm{~N}$, resulting in massive adsorption by this resin. Thus, the connection of XAD 4 and XAD $1600 \mathrm{~N}$ resin was regarded as the optimal choice of in-series macroporous resins, in accord with the results of the static and dynamic adsorption tests.

3.3. Effect of Bed Volume Ratio of Resins. Based on the selection of resins, the bed volume ratio of XAD 4 and XAD $1600 \mathrm{~N}$ resin, one of the main variable factors, must be investigated at a range from $1: 1$ to $5: 1$. Although XAD 4 and $\mathrm{XAD} 1600 \mathrm{~N}$ resins both have the same polarity (nonpolar) and material (polystyrene-divinylbenzene), they possess different dimensional structures (specific surface area, particle diameter, and pore diameter), leading to different adsorption and desorption properties of crocin-I and impurities. Thus, the separation degree and recovery ratio could change significantly with the different bed volume ratios. As shown in Figure 4(a), the bed volume ratio of $3: 1$ showed lower $D_{C-254 \mathrm{~nm}}$ and $D_{C-440 \mathrm{~nm}}$ than the others. Generally speaking, the analysis result indicated that XAD 4 resins played a main role in adsorbing the impurity, shown at $254 \mathrm{~nm}$, to increase the separation degree, while XAD $1600 \mathrm{~N}$ possessed less effect. However, if the bed volume of $\mathrm{XAD} 4$ resins in macroporous resin columns in-series increased too much, there would be more impurities, shown at 
TABle 3: Separation degree $\left(D_{C-254 \mathrm{~nm}}\right.$ and $\left.D_{C-440 \mathrm{~nm}}\right)$ and recovery ratio $(R)$ of crocin-I on four combination of in-series macroporous resins.

\begin{tabular}{lccc}
\hline Selection of macroporous resins & $D_{C-254 \mathrm{~nm}}$ & $D_{C-440 \mathrm{~nm}}$ & $R(\%)$ \\
\hline XAD4 $\sim$ XAD1600N & 0.47 & 0.36 & 42.63 \\
XAD4 $\sim$ ADS-7 & 0.74 & 0.55 & 43.66 \\
XAD4 $\backsim$ HP2MGL & 0.70 & 0.56 & 47.06 \\
XAD4 $\backsim$ XAD7HP & 0.87 & 0.8 & 30.16 \\
Gardenia yellow & 1.92 & 0.71 & \\
\hline
\end{tabular}

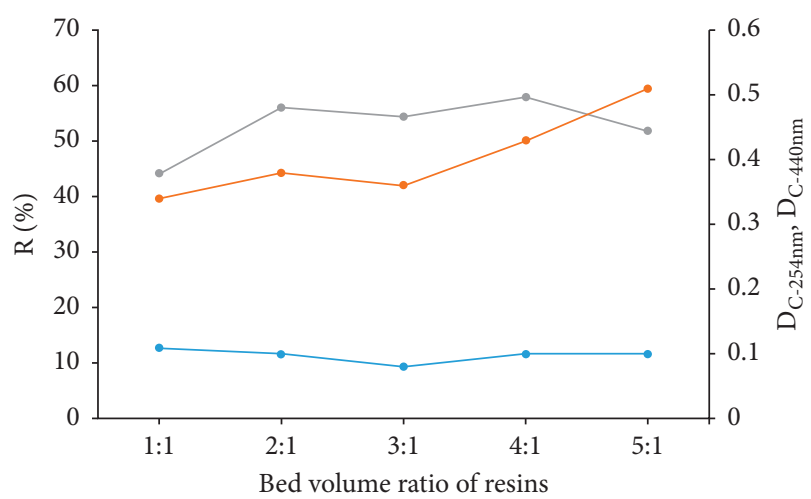

(a)

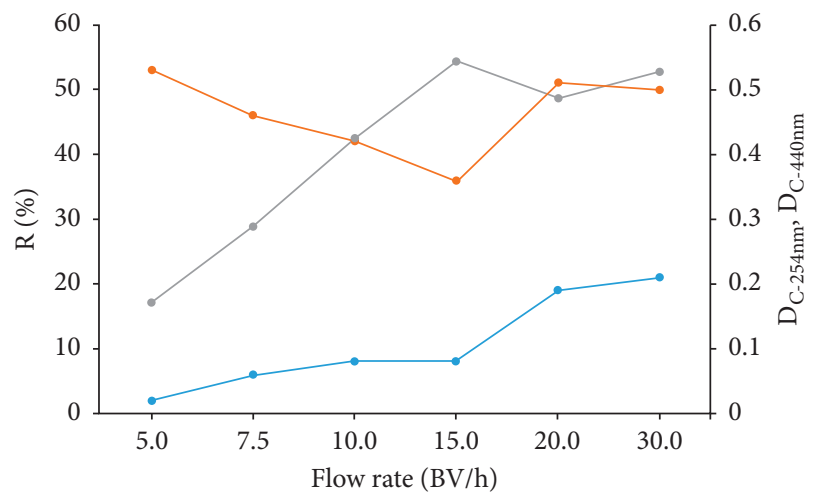

(c)

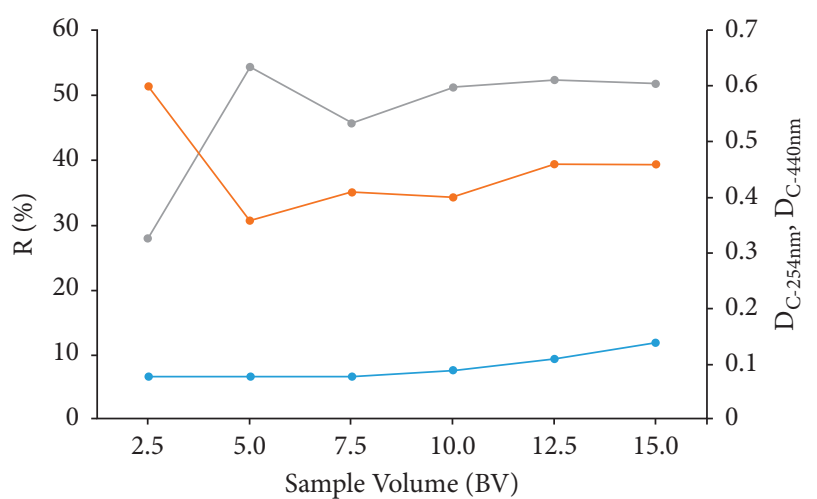

(b)

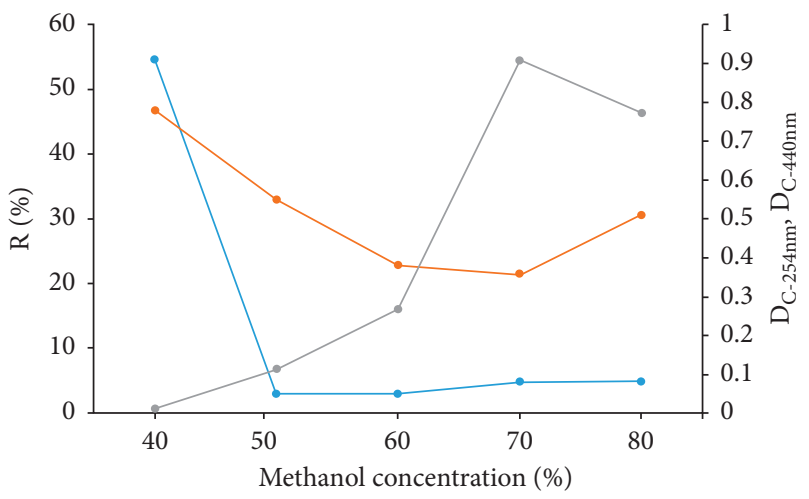

(d)

FIGURE 4: Effect of bed volume ratio of resins (a), sample volume (b), flow rate (c), and methanol concentration (d) on $D_{C-254 \mathrm{~nm}}, D_{C-440 \mathrm{~nm}}$, and $R$ during the process of macroporous resin column in series. - represents $R,-\bullet-$ represents $D_{C-254 \mathrm{~nm}}$, and $-\bullet-$ represents $D_{C-440 \mathrm{~nm}}$.

$440 \mathrm{~nm}$, leading into XAD1600N, which would give the higher $D_{C-440 \mathrm{~nm}}$ and lower purity. Moreover, too little bed volume of XAD 4 resins of in-series macroporous resins would decrease the recovery ratio. Thus, raising the bed volume of XAD 4 resins and reducing that of XAD $1600 \mathrm{~N}$ resins to a certain extent could decrease $D_{C-254 \mathrm{~nm}}$ and $D_{C-440 \mathrm{~nm}}$ significantly, and 3:1 was chosen as the optimal bed volume ratio.

3.4. Effect of Sample Volume. Although the bed volume ratio of the resins was defined, the sample volume could affect the purity and yield of crocin-I significantly. Based on the bed volume of XAD 4 resins, the first resins of the macroporous resin columns in-series, the sample volume was investigated within the range of 2.5-15.0 BV. The effect of the sample volume on $D_{C-254 \mathrm{~nm}}$ and $D_{C-440 \mathrm{~nm}}$ is shown in Figure 4(b). When sample volume reached 5.0 BV, $D_{C-254 \mathrm{~nm}}$ and $D_{C-440 \mathrm{~nm}}$ were lower than the others. It has been reported that multiple partition equilibrium among various phases and the different affinity of resins to crocin-I and impurities play dominant roles in the adsorption process. The more sample volume was loaded on the macroporous resin columns in-series, the more crocin-I and impurities were adsorbed on the resins, resulting in overloaded adsorption, which resulted in lower purity of crocin-I and higher $D_{C-254 \mathrm{~nm}}$ and $D_{C-440 \mathrm{~nm}}$. But when the sample volume was less, the amount of crocin-I loaded on the resins was fewer with the low surface coverage of resins. It made the naked 
acting loci absorb impurities, which decreased the surface energy and made the number of absorbed impurities larger, resulting in high $D_{\mathrm{C}-440 \mathrm{~nm}}$. Thus, 5.0 BV was the optimal choice of sample volume.

3.5. Effect of Flow Rate. The solute flow rate is also of critical importance to affect the chromatographic behaviors, the reaction between solute and resins, the adsorption capacity and desorption ratio, and the purity and yield of crocin-I. According to the size of the separation glass column and the bed volume of resins, the flow rate was investigated within the range of $5 \mathrm{BV} / \mathrm{h}$ to $30 \mathrm{BV} / \mathrm{h}$ to determine the influence of the flow rate on adsorption characteristics. As shown in Figure 4(c), when flow rate increased from $5 \mathrm{BV} / \mathrm{h}$ to $15 \mathrm{BV} /$ h, $D_{C-254 \mathrm{~nm}}$ raised with the unconspicuous increasing trend; in the meantime, $D_{C-440 \mathrm{~nm}}$ reduced and $R$ increased with the growth of flow rate. Then, $D_{C-254 \mathrm{~nm}}$ raised significantly with an increase in flow rate from $20 \mathrm{BV} / \mathrm{h}$ to $30 \mathrm{BV} / \mathrm{h}$. That might be due to the reduced contact time between solute and active sites of the adsorbent at a higher flow rate, leading to incomplete adsorption of crocin-I and impurities on resins [38]. Therefore, $15 \mathrm{BV} / \mathrm{h}$ was selected as the optimal flow rate.

3.6. Effect of Methanol Concentration. The methanol solution was adapted as the eluent to desorb crocin-I from XAD $1600 \mathrm{~N}$ macroporous resins, and the concentration played an important role to affect the separation degree and yield of crocin-I, so methanol concentration was investigated from $40 \%$ to $80 \%(\mathrm{v} / \mathrm{v})$. As shown in Figure $4(\mathrm{~d})$, the $D_{\mathrm{C}-440 \mathrm{~nm}}$ decreased and recovery ratio increased as the methanol concentration increased from $40 \%(\mathrm{v} / \mathrm{v})$ to $70 \%(\mathrm{v} / \mathrm{v})$. On one hand, more crocin-I can be desorbed with the higher methanol concentration owing to the less polarity of methanol than water, leading to the higher desorption ratio. On the other hand, the $D_{C-440 \mathrm{~nm}}$ changed distinctly with the change of methanol concentration because crocin-I can be desorbed more in a high concentration of methanol compared with the impurities shown at $440 \mathrm{~nm}$. However, methanol with over high concentration could simultaneously desorb crocin-I and more impurities, which made $D_{C-440 \mathrm{~nm}}$ larger. Therefore, it had the higher desorption efficiency and purified level of crocin-I in $70 \%$ methanol solution without the effect of the more binding force, leading to a higher recovery ratio, and therefore, $70 \%$ methanol solution was chosen to be the optimal eluent. It could be found that the purity of crocin-I in the eluate was remarkably enhanced compared with that in the initial sample in the HPLC chromatogram (Figure 2).

\subsection{Antidepressant-Like Effect of Crocin-I and Gardenia Yellow}

3.7.1. Effects of Crocin-I and Gardenia Yellow on the Weight, AST, and ALT of Depression Mice. As presented in Table 4, the results demonstrated that the weight of mice in the fluoxetine group grew slowly, which was a significant
TABle 4: Effects of crocin-I $(20,40$, and $70 \mathrm{mg} / \mathrm{kg}$, i.g.) and Gardenia yellow $(30,70$, and $120 \mathrm{mg} / \mathrm{kg}$, i.g.) on the weight, AST, and ALT of mice $(\bar{X} \pm S D)$.

\begin{tabular}{|c|c|c|c|c|}
\hline \multicolumn{2}{|c|}{ Group } & AST & ALT & $\triangle$ weight \\
\hline \multicolumn{2}{|l|}{ Control } & $76.70 \pm 22.58$ & $27.30 \pm 14.80$ & $1.41 \pm 0.65$ \\
\hline \multirow[t]{2}{*}{ Fluoxetine } & $\begin{array}{c}(20 \mathrm{mg} / \\
\mathrm{kg})\end{array}$ & $78.90 \pm 19.89$ & $26.10 \pm 4.31$ & $0.70 \pm 0.97^{*}$ \\
\hline & $\begin{array}{c}(20 \mathrm{mg} / \\
\mathrm{kg})\end{array}$ & $76.10 \pm 32.32$ & $26.80 \pm 6.03$ & $1.35 \pm 0.63$ \\
\hline \multirow[t]{3}{*}{ Crocin-I } & $\begin{array}{c}(40 \mathrm{mg} / \\
\mathrm{kg})\end{array}$ & $72.00 \pm 12.70$ & $21.10 \pm 6.45$ & $2.20 \pm 0.46^{* * *}$ \\
\hline & $\begin{array}{c}(70 \mathrm{mg} / \\
\mathrm{kg})\end{array}$ & $82.22 \pm 12.87$ & $29.20 \pm 12.69$ & $1.51 \pm 0.51$ \\
\hline & $\begin{array}{c}(30 \mathrm{mg} / \\
\mathrm{kg})\end{array}$ & $84.64 \pm 21.37$ & $33.55 \pm 31.98$ & $1.41 \pm 0.50$ \\
\hline \multirow[t]{2}{*}{$\begin{array}{l}\text { Gardenia } \\
\text { yellow }\end{array}$} & $\begin{array}{c}(70 \mathrm{mg} / \\
\mathrm{kg})\end{array}$ & $70.09 \pm 8.46$ & $25.45 \pm 5.79$ & $1.81 \pm 0.86$ \\
\hline & $\begin{array}{c}(120 \mathrm{mg} / \\
\mathrm{kg})\end{array}$ & $76.73 \pm 17.46$ & $31.00 \pm 15.31$ & $1.81 \pm 0.57$ \\
\hline
\end{tabular}

Note: data were expressed as mean \pm SD. ${ }^{*} p<0.05$ and ${ }^{* *} p<0.01$ vs control.

difference from the normal control group, $p<0.05$. Meanwhile, the weight of mice administrating crocin-I $(40 \mathrm{mg} / \mathrm{kg}, p<0.005)$ significantly increased compared with that of the normal control group. And there was no significant difference between the other groups and the control group. According to the result of statistical analysis, crocin-I could improve the condition of slow weight growth, and the effect of an intragastric dose with $40 \mathrm{mg} / \mathrm{kg}$ crocin-I was more obvious, which indicated that medium-dose crocin-I could improve the appetite of depressed mice significantly, which further meant it might have potential efficacy for depression or have fewer adverse effects than fluoxetine. At the same time, there was no significant difference in AST and ALT between the experimental groups and control groups, which revealed that crocin-I and Gardenia yellow both had no significant effect on liver function, which implied that they both had no adverse effect on liver function, like fluoxetine.

3.7.2. Effects of Crocin-I and Gardenia Yellow in the Forced Swimming Tests. Forced swimming tests were carried out as follows: mice were forced to swim individually in a beaker ( $3 \mathrm{~L}, 14 \mathrm{~cm}$ in diameter, and $24 \mathrm{~cm}$ in height) filled with room temperature water to a height of $20 \mathrm{~cm}$, which ensured that mice could not touch the bottom of the container with their tails and hind paws. The pretests were performed by placing mice into the water for 15 minutes, removing them, drying them, and returning to their home cages. After 24 hours, the tests were carried out for 5 minutes. If the mice did not make attempts to escape, the front paws were put together in an upright position, or if they made only movements to remain floating with their heads above the surface of the water, they could be considered immobile. The total time of immobility was recorded during a 5-minute period, which resembled a state of despair and mental depression.

The effects of crocin-I and Gardenia yellow on the total duration of immobility time in the forced swimming tests of 


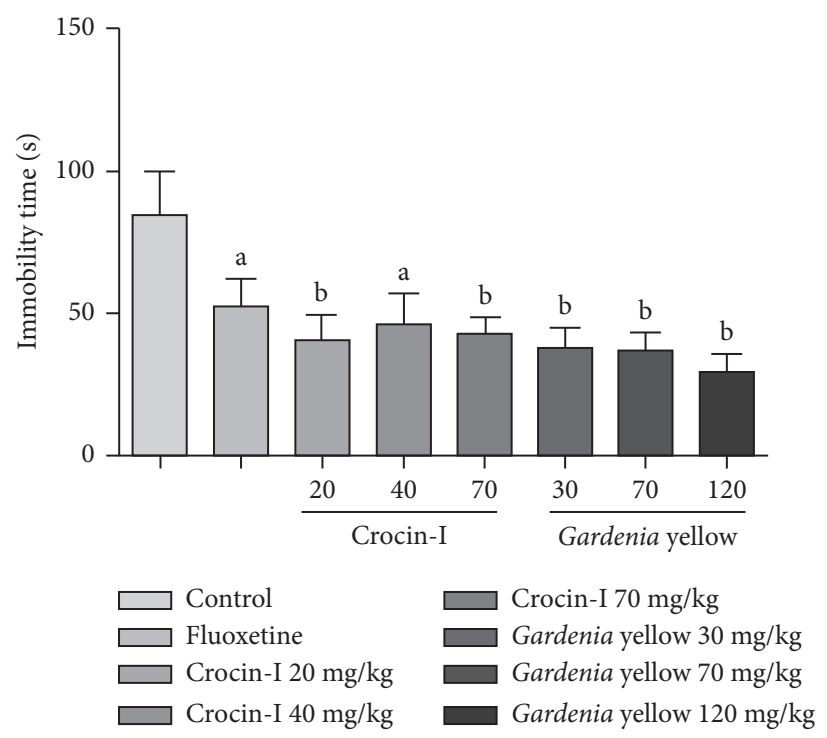

Figure 5: Effect of crocin-I (20, 40, and $70 \mathrm{mg} / \mathrm{kg}$, i.g.) and Gardenia yellow (30, 70, and $120 \mathrm{mg} / \mathrm{kg}$, i.g.) on the total duration immobility time in the force swimming tests of mice. The data were expressed as mean \pm SEM of 11 mice in each group; ${ }^{a} p<0.05$ and ${ }^{b} p<0.001$ vs control group. Positive control mice were treated with fluoxetine $(20 \mathrm{mg} / \mathrm{kg})$.

mice are presented in Figure 5. Ten-day treatment with lowdose and high-dose crocin-I (20 and $70 \mathrm{mg} / \mathrm{kg}$ ) had a more significant effect on immobility time in FST $(p<0.001)$ than that with medium-dose crocin-I $(p<0.05)$. In addition, intragastric administration of Gardenia yellow (30, 70, and $120 \mathrm{mg} / \mathrm{kg}$ ) significantly reduced immobility time in FST $(p<0.001)$, which had no significant difference with fluoxetine. Hence, it could be seen that crocin-I and Gardenia yellow could reduce the total duration of immobility time markedly in the forced swimming tests of mice, the same effect as fluoxetine. According to the results, it can be considered that crocin-I and Gardenia yellow have similar effects on depression with fluoxetine.

\section{Conclusions}

The optimal experimental conditions for purification of crocin-I from Gardenia yellow using macroporous resin columns in-series were as follows: the in-series macroporous resins XAD 4 and XAD $1600 \mathrm{~N}$ resins, the bed volume ratio of $3: 1$, the sample volume of $5.0 \mathrm{BV}$, the flow rate of $15 \mathrm{BV} / \mathrm{h}$, and methanol concentration of $70 \%$. The current study also showed the beneficial effects of crocin-I and Gardenia yellow on depression-like behavior. It seemed that crocin-I had the same efficacy for depression as Gardenia yellow, which could be thought that crocin-I is the main component of Gardenia yellow to treat depression.

\section{Data Availability}

The data used to support the finding of this study are available from the corresponding author upon reasonable request.

\section{Conflicts of Interest}

The authors declare that they have no conflicts of interest.

\section{Acknowledgments}

This work was financially supported by the Key Special Projects of Intergovernmental International Science and Technology Innovation Cooperation (2017YFE0130100) and Natural Science Foundation of China (81703688).

\section{References}

[1] M.-L. He, X.-W. Cheng, J.-K. Chen, and T.-S. Zhou, "Simultaneous determination of five major biologically active ingredients in different parts of Gardenia jasminoides fruits by HPLC with diode-array detection," Chromatographia, vol. 64, no. 11-12, pp. 713-717, 2006.

[2] National Commission of Pharmacopoeia, Pharmacopoeia of the People's Republic of China, p. 249, China Medical Science and Technology Press, Beijing, China, 2020.

[3] S. Yamada, H. Oshima, I. Saito, and J. Hayakawa, "Adsorption of crocetin as an indicator compound for detection of Gardenia yellow in food products (analysis of natural coloring matters in food V)," Food Hygiene and Safety Science (Shokuhin Eiseigaku Zasshi), vol. 37, no. 6, pp. 372-377, 1996.

[4] B. Yang, X. Liu, and Y. Gao, "Extraction optimization of bioactive compounds (crocin, geniposide and total phenolic compounds) from Gardenia (Gardenia jasminoides Ellis) fruits with response surface methodology," Innovative Food Science \& Emerging Technologies, vol. 10, no. 4, pp. 610-615, 2009.

[5] J. W. Shao, J. F. Chen, Y. H. Guo et al., "Water extraction technology and stability of Gardenia yellow pigment," Journal of Shenyang Agricultural University, vol. 37, pp. 857-861, 2006.

[6] C. Wang, J. Ji, L. Wang, and T. Bao, "Technical study on the purification of Gardenia yellow pigment with NKA macroporous adsorption resin," Chemical Industry and Engineering Progress, vol. 22, pp. 622-625, 2003.

[7] J.-F. Chen, G.-M. Fu, Y. Wan et al., "Enrichment and purification of Gardenia yellow from Gardenia jasminoides var. radicans makino by column chromatography technique," Journal of Chromatography B, vol. 893-894, pp. 43-48, 2012. 
[8] T. Q. Pham, F. Cormier, E. Farnworth, V. H. Tong, and M.-R. Van Calsteren, "Antioxidant properties of crocin from Gardenia jasminoides eills and study of the reactions of crocin with linoleic acid and crocin with oxygen," Journal of Agricultural and Food Chemistry, vol. 48, no. 5, pp. 1455-1461, 2000.

[9] Y.-Q. Zheng, J.-X. Liu, J.-N. Wang, and L. Xu, "Effects of crocin on reperfusion-induced oxidative nitrative injury to cerebral microvessels after celebral ischemia," Brain Research, vol. 1138, pp. 86-94, 2007.

[10] A. Vakili, M. R. Einali, and A. R. Bandegi, "Protective effect of crocin against cerebral ischemia in a dose-dependent manner in a rat model of ischemic stroke," Journal of Stroke and Cerebrovascular Diseases, vol. 23, no. 1, pp. 106-113, 2014.

[11] H. Hosseinzadeh, G. Karimi, and M. Niapoor, "Antidepressant effect of Crocus sativus L. stigmas extracts and their constituents, crocin and safranal, in mice," Acta Horticulturae, vol. 650, no. 650, pp. 435-445, 2004

[12] N. Pitsikas, A. Boultadakis, G. Georgiadou, P. A. Tarantilis, and N. Sakellaridis, "Effects of the active constituents of Crocus sativus L., crocins, in an animal model of anxiety," Phytomedicine, vol. 15, no. 12, pp. 1135-1139, 2008.

[13] S.-Y. He, Z.-Y. Qian, F.-T. Tang, N. Wen, G.-L. Xu, and L. Sheng, "Effect of crocin on experimental atherosclerosis in quails and its mechanisms," Life Sciences, vol. 77, no. 8, pp. 907-921, 2005.

[14] I.-A. Lee, J. H. Lee, N.-I. Baek, and D.-H. Kim, "Antihyperlipidemic effect of crocin isolated from the fructus of Gardenia jasminoides and its metabolite crocetin," Biological and Pharmaceutical Bulletin, vol. 28, no. 11, pp. 2106-2110, 2005.

[15] M. Imenshahidi, H. Hosseinzadeh, and Y. Javadpour, "Hypotensive effect of aqueous saffron extract (Crocus sativus L.) and its constituents, safranal and crocin, in normotensive and hypertensive rats," Phytotherapy Research, vol. 24, no. 7, pp. 990-994, 2010.

[16] M. H. Hassan, S. A. Bahashawan, T. M. Abdelghany, G. M. Abd-Allah, and M. M. Ghobara, "Crocin abrogates carbon tetrachloride-induced renal toxicity in rats via modulation of metabolizing enzymes and diminution of oxidative stress, apoptosis, and inflammatory cytokines," Journal of Biochemical and Molecular Toxicology, vol. 29, no. 7, pp. 330-339, 2015.

[17] D. Mohajeri and M. Nazeri, "Inhibitory effect of crocin on hepatic steatosis in the rats fed with high fat diet," Journal of Animal and Veterinary Advances, vol. 11, no. 14, pp. 2373-2379, 2012.

[18] J. Wang, J. Kuai, Z. Luo et al., "Crocin attenuates lipopolysacchride-induced acute lung injury in mice," International Journal of Clinical \& Experimental Pathology, vol. 8, pp. 4844-4850, 2015.

[19] M. Sugiura, Y. Shoyama, H. Saito, and K. Abe, "Crocin (crocetin digentiobiose ester) prevents the inhibitory effect of ethanol on long-term potentiation in the dentate gyrus in vivo," Journal of Pharmacology and Experimental Therapeutics, vol. 271, pp. 703-707, 1994.

[20] H. Hosseinzadeh and H. M. Younesi, "Antinociceptive and anti-inflammatory effects of Crocus sativus L. stigma and petal extracts in mice," BMC Pharmacology, vol. 2, no. 1, p. 7, 2002.

[21] A. M. D’Alessandro, A. Mancini, A. R. Lizzi et al., "Crocus sativus stigma extract and its major constituent crocin possess significant antiproliferative properties against human prostate cancer," Nutrition \& Cancer, vol. 65, pp. 930-942, 2013.

[22] S. Pfister, P. Meyer, A. Steck, and H. Pfander, "Isolation and structure elucidation of carotenoid-glycosyl esters in Gardenia fruit (Gardenia jasminoides eills) and saffron (Crocus sativus linne)," Journal of Agriculture and Food Chemistry, vol. 44, no. 9, pp. 2612-2615, 1996.

[23] H. Pfander and M. Rychener, "Separation of crocetin glycosyl esters by high-performance liquid chromatography," Journal of Chromatography A, vol. 234, no. 2, pp. 443-447, 1982.

[24] M. R. Castellar, H. Montijano, A. Manjón, and J. L. Iborra, "Preparative high-performance liquid chromatographic purification of saffron secondary metabolites," Journal of Chromatography A, vol. 648, no. 1, pp. 187-190, 1993.

[25] H. Zhang, Y. H. Zeng, F. Yan et al., "Semi-preparative isolation of crocins from saffron (Crocus sativus L.)," Chromatographia, vol. 59, pp. 691-696, 2004.

[26] J. Feng, X. He, S. Zhou et al., "Preparative separation of crocins and geniposide simultaneously from Gardenia fruits using macroporous resin and reversed-phase chromatography," Journal of Separation Science, vol. 37, no. 3, pp. 314-322, 2014.

[27] L. Wang, S. Liu, X. Zhang, J. Xing, Z. Liu, and F. Song, "A strategy for identification and structural characterization of compounds from Gardenia jasminoides by integrating macroporous resin column chromatography and liquid chromatography-tandem mass spectrometry combined with ionmobility spectrometry," Journal of Chromatography A, vol. 1452, pp. 47-57, 2016.

[28] Z. Liang, M. Yang, X. Xu et al., "Isolation and purification of geniposide, crocin-1, and geniposidic acid from the fruit of Gardenia jasminoides eills by high-speed counter-current chromatography," Separation Science and Technology, vol. 49, no. 9, pp. 1427-1433, 2014.

[29] K. Babic, L. V. D. Ham, and A. D. Hann, "Recovery of benzaldehyde from aqueous streams using extractant impregnated resins," Reactive and Functional Polymer, vol. 66, pp. 1494-1505, 2006.

[30] G. Liu, S. Zheng, D. Yin, Z. Xu, and J. Fang, “Adsorption of aqueous alkylphenol ethoxylate surfactants by mesoporous carbon CMK-3," Journal of Colloid and Interface Science, vol. 302 , no. 1, pp. 47-53, 2006.

[31] H. Li and Z. Wang, "Enrichment and purification of polyphenols in pine cone extracts of Pinus koraiensis Sieb. et zucc. using a novel multi-channnel parallel-serial chromatographic system packed with macroporous resin," RSC Advances, vol. 5, no. 39, pp. 30711-30718, 2015.

[32] H.-L. Ye, Y.-F. Liu, X.-H. Zhang, and D.-L. Di, "DFT study on hydrogen-bonding adsorption mechanism of rutin onto macroporous adsorption resins functionalized with amino, hydroxyl, and carboxyl groups," Structural Chemistry, vol. 24, no. 5, pp. 1443-1449, 2013.

[33] Y. Liu, D. Di, Q. Bai et al., "Preparative separation and purification of rebaudioside A from steviol glycosides using mixed-mode macroporous adsorption resins," Journal of Agricultural and Food Chemistry, vol. 59, no. 17, pp. 96299636, 2011.

[34] Z. Chen, X. Wei, J. Li, and D. Di, "Preparative separation of rebaudioside A from commercialized steviol glycosides by macroporous adsorption resins mixed bed," Separation and Purification Technology, vol. 89, pp. 22-30, 2012.

[35] J. Li, Z. Chen, and D. Di, "Preparative separation and purification of rebaudioside A from Stevia rebaudiana bertoni crude extracts by mixed bed of macroporous adsorption resins," Food Chemistry, vol. 132, no. 1, pp. 268-276, 2012.

[36] Y. Zhao, Z. Chen, D. Liu, J. Long, and D. Di, "Separation of flavonoids in the leaves of Sophora japonica by macroporous adsorption resin mixed-bed technology," Pigment \& Resin Technology, vol. 46, no. 3, pp. 235-243, 2017. 
[37] J. N. Crawley, "What's wrong with my mouse? behavioral phenotyping of transgenic and knockout mice," Genes Brain and Behavior, vol. 1, pp. 131-134, 2002.

[38] G. Dhanarajan, V. Rangarajan, and R. Sen, "Dual gradient macroporous resin column chromatography for concurrent separation and purification of three families of marine bacterial lipopeptides from cell free broth," Separation and $\mathrm{Pu}$ rification Technology, vol. 143, pp. 72-79, 2015. 